\title{
Evaluation of folate concentration in amniotic fluid and maternal and umbilical cord blood during labor
}

Joanna Suliburska ${ }^{1}$, Rafał Kocyłowski², Mariusz Grzesiak², Zuzanna Gaj², Benny Chan³, Constantin von Kaisenberg ${ }^{4}$, Yvonne Lamers ${ }^{3,5}$

\author{
${ }^{1}$ Institute of Human Nutrition and Dietetics, Poznan University of Life Sciences, \\ Poznan, Poland \\ 2Department of Perinatology and Gynecology, Polish Mother's Memorial Hospital \\ Research Institute, Lodz, Poland \\ ${ }^{3}$ Food, Nutrition and Health Program, Faculty of Land and Food Systems, \\ The University of British Columbia, Vancouver, British Columbia, Canada \\ ${ }^{4}$ Klinik für Frauenheilkunde und Geburtshilfe Pränatalmedizin (MVZ) Medizinische \\ Hochschule Hannover, Germany \\ ${ }^{5}$ British Columbia Children's Hospital Research Institute, Vancouver, British Columbia, \\ Canada
}

Submitted: 1 August 2018

Accepted: 8 September 2018

Arch Med Sci 2019; 15 (6): 1425-1432

DOI: https://doi.org/10.5114/aoms.2018.78776

Copyright $\odot 2018$ Termedia \& Banach

\begin{abstract}
Introduction: Folate is required for fetal, placental and maternal tissue growth during pregnancy. A decline in maternal circulating folate concentrations and an increase in total homocysteine (a non-specific indicator of folate deficiency) have been observed with the progression of pregnancy. However, the role of folate in the third trimester of pregnancy is not clear and folate status in late pregnancy has not so far been widely analyzed. The main aim of this retrospective cross-sectional study was to determine the folate concentrations in amniotic fluid and in maternal and umbilical cord blood serum derived during delivery.

Material and methods: This study was conducted on 175 pregnant Polish women (white/Caucasian) aged between 17 and 42 years. Only pregnancies without birth defects were included in this study. Amniotic fluid, maternal serum, and umbilical cord blood samples were collected during vaginal delivery or cesarean section. Folate concentration was determined using a microbiological assay.

Results: Strong correlations were observed between the concentrations of folate in amniotic fluid and maternal serum (rho $=0.67, p<0.001$ ) and amniotic fluid and cord blood serum (rho $=0.49, p<0.001$ ) and between maternal serum and cord blood serum (rho $=0.67, p<0.001$ ). Folate concentrations in amniotic fluid were significantly associated with maternal age (rho $=0.19, p<0.05$ ). Pre-pregnancy body mass index and maternal weight/neonatal birth weight ratio were independent predictors of folate concentrations in maternal serum $(\beta=0.33, p<0.05 ; \beta=-0.19, p<0.05)$ and amniotic fluid $(\beta=0.28, p<0.05 ; \beta=-0.19, p<0.05)$ in late pregnancy. Conclusions: Folate concentrations in amniotic fluid are associated with maternal and neonatal folate status peripartum in healthy women.
\end{abstract}

Key words: folate, amniotic fluid, umbilical cord blood, maternal serum, delivery.

\author{
Corresponding author: \\ Joanna Suliburska MD, PhD \\ Institute of Human Nutrition \\ and Dietetics \\ Poznan University \\ of Life Sciences \\ Wojska Polskiego 31 \\ 60-637 Poznan, Poland \\ Fax: +48512 516764 \\ E-mail: jsulibur@up.poznan.pl
}




\section{Introduction}

Folate plays a crucial role in cell division and the synthesis, repair and methylation of DNA [1]. Therefore, folate requirements increase in stages of rapid growth, including during pregnancy [2]. Moreover, folate is important for normal neurodevelopment as well as mental and emotional health in a developing child [2]. The clinical symptom of folate deficiency is megaloblastic anemia. Folate deficiency has been associated with an increased risk of cancer and neural tube defects $[1,2]$. Periconceptional folic acid supplementation has been shown to reduce the incidence of neural tube defects [2] and has been associated with a reduced risk of preeclampsia, congenital heart diseases and preterm birth [3-6]. Supplementation with folic acid is recommended before conception and during early pregnancy; however, the role of folate status in late pregnancy is not clear. Folic acid supplementation throughout pregnancy increases maternal serum and cord blood folate concentration and prevents an increase in plasma total homocysteine concentration in late pregnancy [7].

In many studies, maternal folate status has been determined by assessment of folate concentration in a mother's serum or red cells and in some cases in cord blood serum $[8,9]$. There are only a few studies in which folate level in amniotic fluid has been determined. These authors determined B-vitamins and their metabolites in amniotic fluid and other biospecimens and found that amniotic fluid may be a good matrix to identify folate status during pregnancy $[10,11]$. Previous studies have been conducted in different stages of pregnancy and usually to identify if there is a relationship between folate deficiency and abnormal fetal development or birth defects [12-14].

The composition of amniotic fluid is important for fetal development and reflects both maternal and fetal compartments [15]. The concentrations of folate in amniotic fluid result from placental transfer, fetal renal excretion and diffusion through the non-keratinized fetal skin [10, 15]. An analysis of the content of amniotic fluid can provide important information on the health status of the mother and her fetus at different stages of gestation $[10,15]$. To date, there are no reference values for folate concentrations in amniotic fluid of healthy pregnant women or in cord blood of normal pregnancies.

The most convenient time to collect amniotic fluid and maternal and cord blood samples simultaneously is during delivery. Knowledge about folate status in mother and fetus and about potential interactions between these two organisms as expressed by amniotic fluid content is currently lacking. Therefore, the primary objective of this study was to determine the concentration of folate in amniotic fluid, maternal serum, and cord blood at birth. The secondary objectives were to test for correlations between folate concentrations in the three compartments and to determine the association between folate concentrations and maternal and newborn characteristics.

\section{Material and methods}

\section{Study design and participants}

This was a retrospective cross-sectional study to assess folate concentrations of amniotic fluid, maternal serum, and serum obtained from the umbilical cord of term neonates born between 38 and 42 weeks of gestation. The amniotic fluid, maternal blood and umbilical cord blood were collected at the same time at birth during routine diagnostic and treatment procedures in pregnant women hospitalized in the Polish Mother's Memorial Hospital Research Institute. The collected samples were stored at $-80^{\circ} \mathrm{C}$.

The study was conducted in pregnant Polish women (white/Caucasian) who were under routine obstetric care. Women voluntarily participated in the study after signing an informed consent form. The participants consented to secondary use of their samples. The study was conducted on patients qualified on the basis of inclusion and exclusion criteria.

The inclusion criteria were normal intrauterine pregnancy without apparent congenital anomalies evaluated by ultrasound or prenatal tests, and a lack of signs and symptoms of maternal or fetal infection or anemia. The exclusion criteria were vaginal bleeding, pelvic pain, chorionic hematoma, premature rupture of membranes (PROM), placental insufficiency, multiple pregnancy, maternal diabetes, hypertension in pregnancy, obstetric history of miscarriages and fetal growth disorders (growth restriction, macrosomia), birth defects or genetic conditions in the current pregnancy or present in the women, current use of medicines or supplements that affect the folate balance in the organism and maternal exposure to alcohol, drugs, or tobacco smoke.

The study was approved by the Bioethics Commission of the Research Ethical Committee of Polish Mother's Memorial Hospital Research Institute in Poland (approval no. 50/2016) and the University of British Columbia Clinical Research Ethics Board (UBC CREB, H16-00419) and was, therefore, performed in accordance with the ethical standards laid down in the 1964 Declaration of Helsinki and its later amendments.

After participants were enrolled in the study, a routine medical interview was conducted to 
collect data on maternity, pregnancy, family history of illnesses and operations, drugs and medications used, and the occurrence of allergies. Maternal weight was measured before delivery to the nearest $0.1 \mathrm{~kg}$ using a calibrated digital weight scale while women were wearing lightweight clothing. Maternal height was measured in $\mathrm{cm}$ and pre-pregnancy weight was self-reported. The pre-pregnancy body mass index (BMI) was calculated. Birth weight of the newborns was assessed using a digital weight scale in the third stage of delivery. Week of gestation was determined by first trimester obstetric ultrasonography. Newborn health was assessed by the Apgar score.

\section{Biospecimen collection and folate measurement}

Blood samples were collected from a vein of the pregnant women at the time of delivery and from the umbilical cord postpartum. Monovette test tubes (Neutral or Serum Z/7.5 ml; Sarstedt, Sarstedt AG \& Co, Nümbrecht, Germany) were used without any anticoagulants to obtain blood serum and these were spun for $30 \mathrm{~min}(3,000 \mathrm{rpm} / \mathrm{min}$ at $4^{\circ} \mathrm{C}$ ) and frozen. All serum samples were stored at $-80^{\circ} \mathrm{C}$.

Amniotic fluid samples were obtained $(5 \mathrm{ml})$ by transabdominal puncture in the surgery wound during cesarean sections or transvaginal puncture using a speculum when cervical dilatation was above $4 \mathrm{~cm}$ during vaginal births, in both situations with intact membranes, using sterile needles and syringes just before delivery. The samples were centrifuged $(3,000 \mathrm{rpm} / \mathrm{min}$ for $10 \mathrm{~min}$ at $\left.4^{\circ} \mathrm{C}\right)$, frozen, and stored at $-80^{\circ} \mathrm{C}$.

Biospecimens were shipped on dry ice to the University of British Columbia (UBC), UBC Nutritional Biomarker Laboratory, for folate analyses. Amniotic fluid and maternal and cord blood serum folate concentrations were determined using the microbiological folate assay with chloramphenicol-resistant Lactobacillus casei as the test microorganism, as described by Molloy and Scott [16] and O'Broin and Kelleher [17]. The study samples were analyzed over 11 consecutive days. The inter-assay variations for whole blood and serum folate concentrations were $10 \%$ and $5.9 \%$, respectively. Whole blood hemolysate (NIBSC code: 95/528) served as an external quality control; the measured mean folate concentration was 12.8 $\mathrm{ng} / \mathrm{ml}$ (target value $13 \mathrm{ng} / \mathrm{ml}$ ) with an inter-assay variation of $7.8 \%$.

\section{Statistical analysis}

All statistical analyses were performed with Statistica 10 for Windows. Data were tested for normal distribution using the Shapiro-Wilk test. The Mann-Whitney test and ANOVA Kruskal-Wallis and Duncan's tests were used to compare differences between groups for all the studied parameters. The associations between parameters were calculated using Spearman's rank correlation coefficient. Regression analyses were used to assess the relationships between variables. The level of statistical significance was set to $p<0.05$.

\section{Results}

The characteristics of the participants are presented in Table I. The study population consisted of a total of 175 examined deliveries by healthy

Table I. Maternal and newborn characteristics

\begin{tabular}{|c|c|}
\hline Variable & All participants \\
\hline Number of women & 175 \\
\hline Age of mother [years] & $\begin{array}{c}29.5 \pm 4.6 \\
30 \\
17-42\end{array}$ \\
\hline Maternal weight pregnancy [kg] & $\begin{array}{c}76.8 \pm 11.8 \\
75 \\
53-124\end{array}$ \\
\hline Pre-pregnancy BMI $\left[\mathrm{kg} / \mathrm{m}^{2}\right]$ & $\begin{array}{c}22.3 \pm 3.7 \\
21.5 \\
16.3-37.8\end{array}$ \\
\hline Gestational age at birth & $\begin{array}{c}39.1 \pm 1.2 \\
39 \\
38-42\end{array}$ \\
\hline \multicolumn{2}{|l|}{ Number of past, live childbirths: } \\
\hline 0 & $51 \%$ \\
\hline 1 & $28 \%$ \\
\hline 2 & $12 \%$ \\
\hline 3 & $4 \%$ \\
\hline$\geq 4$ & $5 \%$ \\
\hline \multicolumn{2}{|l|}{$\begin{array}{l}\text { Number of miscarriages in previous } \\
\text { pregnancies: }\end{array}$} \\
\hline 0 & $80 \%$ \\
\hline 1 & $15 \%$ \\
\hline 2 & $5 \%$ \\
\hline Vaginal delivery & $73 \%$ \\
\hline Caesarean section & $27 \%$ \\
\hline Neonatal sex (male/female) & $103 / 72$ \\
\hline Birth weight [g] & $\begin{array}{c}3367 \pm 405.9 \\
3350 \\
2350-5000\end{array}$ \\
\hline Apgar score & $\begin{array}{c}9.5 \pm 0.6 \\
10 \\
7-10\end{array}$ \\
\hline
\end{tabular}

Data are presented as mean $\pm S D$, median, and minimum-maximum. 
Table II. Folate concentration in amniotic fluid and maternal and umbilical cord serum in all participants and categorized by maternal and neonatal characteristics

\begin{tabular}{|c|c|c|c|c|c|}
\hline Characteristic & $\begin{array}{l}\text { Sample } \\
\text { size }\end{array}$ & Parameter & $\begin{array}{l}\text { Amniotic fluid } \\
\text { [nmol] }\end{array}$ & $\begin{array}{l}\text { Maternal serum } \\
{[\mathrm{nmol}]}\end{array}$ & $\begin{array}{l}\text { Umbilical cord } \\
\text { serum [nmol] }\end{array}$ \\
\hline All participants & $n=175$ & $\begin{array}{c}\text { Mean } \pm \text { SD } \\
\text { Median } \\
\text { Min. }- \text { max. } \\
5^{\text {th }}-95^{\text {th }} \text { percentile }\end{array}$ & $\begin{array}{l}11.9 \pm 6.8^{A} \\
10.3 \\
2.5-33.1 \\
3.4-22.9\end{array}$ & $\begin{array}{c}53.5 \pm 27.7^{B} \\
52.3 \\
5.0-131.4 \\
13.8-101.6\end{array}$ & $\begin{array}{l}83.5 \pm 30.1^{c} \\
77.4 \\
23.5-175.1 \\
38.1-136.1\end{array}$ \\
\hline \multirow[t]{2}{*}{ Maternal age } & $\begin{array}{c}\leq 30 \\
n=88\end{array}$ & $\begin{array}{l}\text { Mean } \pm \text { SD } \\
\text { Median } \\
\text { Min.-max. }\end{array}$ & $\begin{array}{c}10.4 \pm 6.4^{a} \\
9.2 \\
2.5-32.8\end{array}$ & $\begin{array}{c}51.5 \pm 29.8 \\
50.3 \\
5-109.3\end{array}$ & $\begin{array}{c}79.7 \pm 30.9 \\
79.5 \\
23.5-171.5\end{array}$ \\
\hline & $\begin{array}{c}>30 \\
n=87\end{array}$ & $\begin{array}{l}\text { Mean } \pm \text { SD } \\
\text { Median } \\
\text { Min.-max. }\end{array}$ & $\begin{array}{c}13.3 \pm 6.9^{b} \\
11.3 \\
2.7-33.1 \\
\end{array}$ & $\begin{array}{c}55.4 \pm 25.7 \\
51.5 \\
11.8-131.4 \\
\end{array}$ & $\begin{array}{l}84.6 \pm 29.5 \\
82.4 \\
27.3-175.1 \\
\end{array}$ \\
\hline \multirow[t]{2}{*}{ Neonatal sex } & $\begin{array}{c}\text { Male } \\
n=103\end{array}$ & $\begin{array}{l}\text { Mean } \pm \text { SD } \\
\text { Median } \\
\text { Min.-max. }\end{array}$ & $\begin{array}{c}12.0 \pm 7.1 \\
10.4 \\
2.5-33.1\end{array}$ & $\begin{array}{c}55.1 \pm 27.3 \\
55.0 \\
11.6-109.3\end{array}$ & $\begin{array}{c}83.9 \pm 32.8 \\
82.0 \\
23.5-175.1\end{array}$ \\
\hline & $\begin{array}{l}\text { Female } \\
n=72\end{array}$ & $\begin{array}{l}\text { Mean } \pm \text { SD } \\
\text { Median } \\
\text { Min.-max. }\end{array}$ & $\begin{array}{c}12.0 \pm 6.4 \\
10.0 \\
2.5-32.8\end{array}$ & $\begin{array}{c}51.1 \pm 28.1 \\
46.6 \\
5-131.4\end{array}$ & $\begin{array}{c}79.9 \pm 25.7 \\
78.0 \\
27.3-164.6\end{array}$ \\
\hline \multirow[t]{2}{*}{$\begin{array}{l}\text { Maternal weight } \\
\text { at birth/birth } \\
\text { weight }(\mathrm{kg})\end{array}$} & $\begin{array}{l}<22 \\
n=68\end{array}$ & $\begin{array}{l}\text { Mean } \pm \text { SD } \\
\text { Median } \\
\text { Min.-max. }\end{array}$ & $\begin{array}{c}13.2 \pm 7.6 \\
11.6 \\
2.5-33.1 \\
\end{array}$ & $\begin{array}{c}57.4 \pm 27.2 \\
55.7 \\
7.4-131.4 \\
\end{array}$ & $\begin{array}{c}86.6 \pm 29.6 \\
86.7 \\
35.3-175.1 \\
\end{array}$ \\
\hline & $\begin{array}{c}>22 \\
n=107\end{array}$ & $\begin{array}{l}\text { Mean } \pm \text { SD } \\
\text { Median } \\
\text { Min.-max. }\end{array}$ & $\begin{array}{c}11.1 \pm 6.2 \\
10.4 \\
2.5-30.3\end{array}$ & $\begin{array}{c}51.2 \pm 28.1 \\
51.8 \\
5-127.7\end{array}$ & $\begin{array}{c}79.3 \pm 30.4 \\
77 \\
23.5-147.8\end{array}$ \\
\hline \multirow[t]{2}{*}{ Type of delivery } & $\begin{array}{c}\text { Caesarean } \\
\text { section } \\
n=47\end{array}$ & $\begin{array}{l}\text { Mean } \pm \text { SD } \\
\text { Median } \\
\text { Min.-max. }\end{array}$ & $\begin{array}{c}12.0 \pm 6.6 \\
11.3 \\
3.1-33.1\end{array}$ & $\begin{array}{c}54.8 \pm 28.9 \\
53.3 \\
7.4-131.4\end{array}$ & $\begin{array}{c}81.6 \pm 29.7 \\
79.8 \\
35.3-175.1\end{array}$ \\
\hline & $\begin{array}{l}\text { Vaginal } \\
\text { delivery } \\
n=128\end{array}$ & $\begin{array}{l}\text { Mean } \pm \text { SD } \\
\text { Median } \\
\text { Min.-max. }\end{array}$ & $\begin{array}{c}11.8 \pm 7.5 \\
10.6 \\
2.5-32.8\end{array}$ & $\begin{array}{c}54.2 \pm 24.8 \\
52.6 \\
5-128.8\end{array}$ & $\begin{array}{c}84.0 \pm 32.4 \\
82.0 \\
23.5-164.6\end{array}$ \\
\hline
\end{tabular}

SD - standard deviation, ${ }^{A-C}$ Different letters indicate statistically significant difference between biospecimens; ANOVA Kruskal-Wallis and Duncan's test $p<0.05{ }^{a, b}$ Different letters indicate statistically significant difference in folate concentration of the same biospecimen between subgroups; Mann-Whitney test $p<0.01$.

women with singleton pregnancies in cephalic fetal presentation without birth defects. Seventy-three percent had a normal vaginal birth and $27 \%$ delivered by cesarean section. In terms of neonatal sex, 103 (59\%) newborns were male and 72 (41\%) were female. The median \pm SD maternal age was $29.5 \pm 4.6$ years (minimum-maximum: $17-42$ years). Over $80 \%$ of the women had secondary and higher education and they declared their socioeconomic status as good or very good.

Concentrations of folate in amniotic fluid and maternal serum and umbilical cord serum are shown in Table II. Folate concentrations significantly differed in the three assessed compartments at delivery. The highest folate concentration was found in umbilical cord blood $(83.5 \pm 30.1$ $\mathrm{nmol} / \mathrm{l})$ and the lowest in amniotic fluid (11.9 \pm 6.8 $\mathrm{nmol} / \mathrm{l})$. Folate concentrations in all three compartments did not differ between categories of maternal weight at delivery/neonatal birth weight ratio, type of delivery, or neonatal sex.

Folate concentrations were significantly correlated between amniotic fluid, maternal serum and umbilical cord serum (Figure $1 \mathrm{~A}-\mathrm{C}$ ). The strongest correlation was between amniotic fluid and maternal serum folate concentrations (rho $=0.67$ ). A positive but weak correlation was observed between amniotic fluid folate concentration and maternal age (rho $=0.19$ ). The highest folate concentration in amniotic fluid was observed in women aged 31-35 years (Figure 2). The results of the regression analysis showed that pre-pregnancy BMI and maternal weight at delivery/neonatal birth weight ratios were independent predictors (along with age of mother and maternal body mass) of folate concentrations in amniotic fluid and maternal serum (Table III).

\section{Discussion}

In this study, we determined the range of folate concentrations collected during delivery in different biological compartments: amniotic fluid, maternal serum and umbilical cord blood. Strong correlations were found between folate concentrations in all types of samples. We also found that the concentration of folate in amniotic fluid was associated with maternal age, and that pre-pregnancy BMI and maternal weight at delivery/neo- 
A

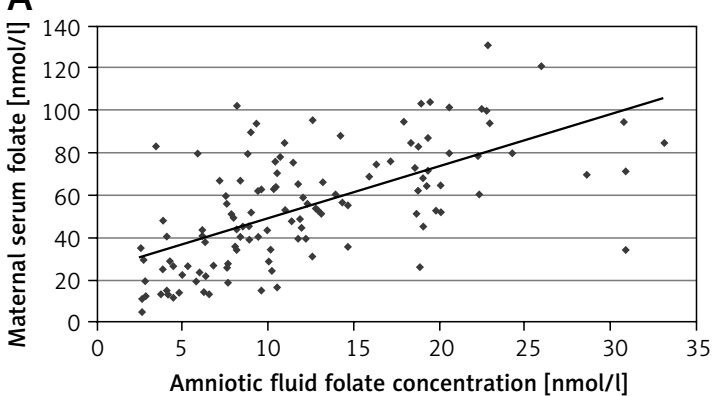

C

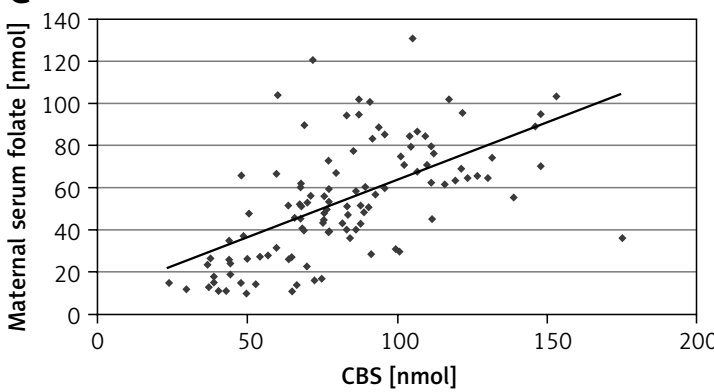

natal birth weight ratios were independent predictors of folate concentration in amniotic fluid and maternal serum. To the best of our knowledge, this is the first study on healthy pregnant women to demonstrate these relationships at delivery.

The strong correlation between folate concentration in amniotic fluid and maternal and cord blood serum shows a functional connection and dependence between maternal and fetal organisms provided by the placenta. In other European populations, there have been lower mean concentrations of folate in maternal serum and cord blood compared to our results; however, interestingly and similar to this study, the concentration of folate in cord blood serum was also nearly $60 \%$ higher than in maternal serum [18]. A lower level of folate in amniotic fluid compared to maternal serum has previously been reported in animal studies [12-14, 17]. Ahn [19] found that folate levels in umbilical cord blood were twice those of maternal serum and the folate level in

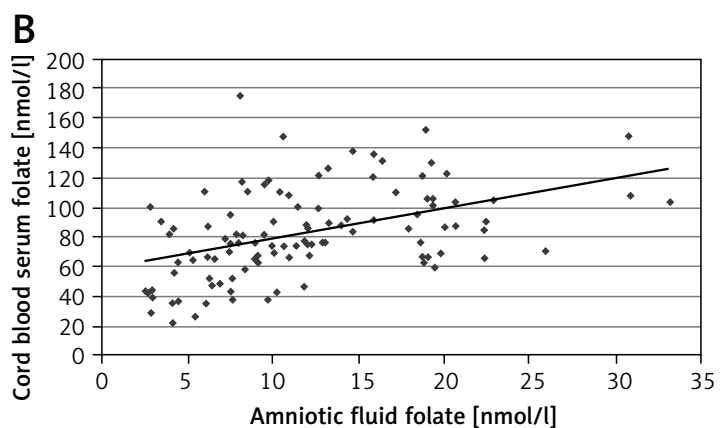

Figure 1. A - Significant correlation between total folate concentration in amniotic fluid and in maternal serum (rho $=0.67, p<0.001$ ). B - Significant correlation between total folate concentration in amniotic fluid and in umbilical cord serum (rho $=0.49, p<0.001)$. C - Significant correlation between total folate concentration in maternal serum and in umbilical cord serum (rho $=0.67, p<0.001)$

placenta was even higher (on average $998 \mathrm{ng} / \mathrm{g}$ ). Maternal folate concentration has a positive correlation with cord blood and placenta tissue. Folate concentrations in cord blood change on the basis of the gestational age and maternal nutritional status. In women with a low folate status the folate level in the fetus is still greater than in

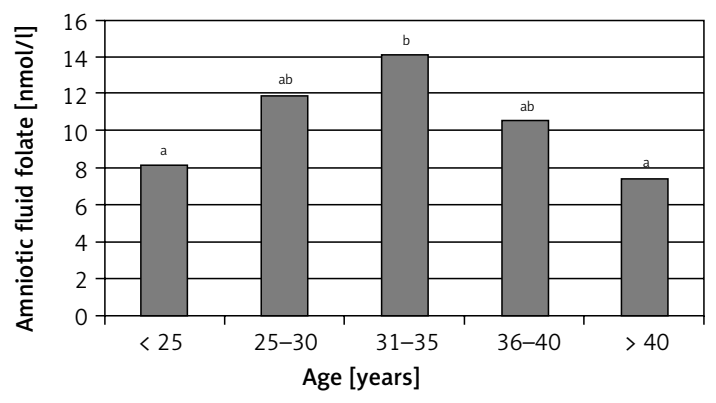

Figure 2. Folate concentration in amniotic fluid according to maternal age

$a, b$ Significant differences between groups $p<0.05$; ANOVA Kruskal-Wallis and Duncan's test.

Table III. Predictors of folate concentration in amniotic fluid and maternal serum ( $\beta$-coefficient)

\begin{tabular}{|lcc|}
\hline Parameter & Amniotic fluid & Maternal serum \\
\hline Maternal age & 0.05 & -0.13 \\
\hline Maternal body weight at delivery & -0.16 & 0.18 \\
\hline Maternal body weight/newborn birth weight & $-0.19^{*}$ & $-0.19^{*}$ \\
\hline Pre-pregnancy BMI & $0.33^{*}$ & $0.28^{*}$ \\
\hline Amniotic fluid folate concentration & - & $0.49^{\star *}$ \\
\hline Maternal serum folate concentration & $0.61^{* *}$ & - \\
\hline Cord blood serum folate concentration & 0.07 & $0.38^{\star *}$ \\
\hline${ }^{*}=0.05^{* *} p=0.01 . B M I-$ body mass index & & \\
\hline
\end{tabular}


the mother's blood. This indicates that folate may be accumulated in the placenta or umbilical cord from the maternal organism and then transported to the fetus [19]. This mechanism may be responsible for maintaining the fetal level above that of the maternal supply. Moreover, folate transfer from maternal blood to the fetus depends on the activity of transporters (FOLR1, RFC1, HCP1/PCFT) in the placenta. The amount of these transporters decreases along with duration of pregnancy [20].

Comparing the results, we found higher folate concentrations in amniotic fluid and maternal serum than those observed in pregnant European women at mid-pregnancy $[11,21]$. In some studies, folate content in amniotic fluid at earlier weeks of pregnancy was slightly lower than in women at late pregnancy [22]. However, in the second trimester a decreasing folate level has also been observed in maternal and fetal tissues connected with advancing gestational age of pregnancy $[10,11,21]$. The decreasing content of folate in maternal samples connected with the duration of the pregnancy may be related to the fact that pregnant women usually take a folic acid supplement in the first months of pregnancy and then discontinue supplementation in later pregnancy. Such behavior is consistent with international guidelines and clinical practice in Poland, with the recommendation to start periconceptional folic acid supplementation at least 1 month prior to pregnancy and to continue this until the end of the first trimester to prevent neural tube defects [23-25]. Furthermore, fetal growth and development in later pregnancy may increase the demand for folate, and decreases in the level of this vitamin in maternal tissue may be a consequence of this. In some studies, higher maternal folate concentrations during pregnancy are associated with higher gestational age at birth, lower preterm birth risk and lower weight outcome, but other studies do not confirm these associations [26-28]. In this study, we found that pre-pregnancy BMI and mother/newborn weight ratios at birth are strong predictors of folate concentrations in maternal serum and amniotic fluid. Our results showed that high BMI before pregnancy and an increase in maternal body weight in relation to neonatal birth weight may lead to a decrease in folate status. Previous studies have shown an inverse correlation between pre-pregnancy $\mathrm{BMI}$ and folate serum in pregnant women $[9,29]$. These findings may be explained by results obtained by Stern et al. [30], who found that obesity may modify folate pharmacokinetics. Folate status in women who are overweight/obese may be a possible contributor to increases in the risk of congenital birth defects [31-33].

Human and experimental studies have shown that supplementation with folic acid reduced the risk of preterm delivery and low birth weight [13]. A recent study found that continued supplementation with folic acid in the second and third trimesters can prevent a decline in maternal folate status resulting from increased folate requirements during pregnancy $[23,34]$.

According to the literature, folate status in women is related to their age. Low dietary folate intake and low biochemical folate status have been found in younger women compared to women over 30 years of age [35-37]. The results of our study confirm that age is associated with folate status. The concentration of folate in amniotic fluid was significantly higher in women older than 30 years compared to those aged $\leq 30$ years. Results of other studies have shown that low folate status in pregnant women is determined by younger maternal age, lower educational level and lower annual income [38]. In our study, socioeconomic status did not affect folate concentration in women, because we had a rather homogeneous group (nearly $70 \%$ had higher education and over $80 \%$ declared their socioeconomic status as good or very good). Moreover, older maternal age was reported to predict more frequent use of supplements during pregnancy [38, 39].

There are some limitations to the current study that should be mentioned. First of all, we analyzed folate concentrations in serum, which is a short-term indicator of folate; red blood cell folate level provides a better estimation of folate status but was not measured in this study. Age cut-off (30 years) and age range and mother/ neonate weight ratio cut-off (value 22) in subgroups were established mainly by considering the size of the groups. Another limitation is the lack of dietary data and knowledge about the women's supplement use. In addition, the results apply only to healthy women without any complications during pregnancy. Future studies may consider maternal diseases, pregnancy complications and birth defects to investigate possible correlations these factors might have with maternal and newborn folate status.

In conclusion, the determination of folate concentration in amniotic fluid simultaneously with maternal and umbilical cord serum at birth showed a strong correlation between these three analyzed compartments, with the highest levels of folate in cord blood and the lowest in amniotic fluid.

\section{Acknowledgments}

This work was supported by the Dekaban Foundation, the Faculty of Land and Food Systems, University of British Columbia, Vancouver, Canada and also by the Department of Perinatology and Gynecology, Polish Mother's Memorial 
Hospital Research Institute, Lodz, Poland (Grant No. 2016/l/18-GW). The funding source had no involvement in the study design, in the collection, analysis and interpretation of data, in the writing of the report, or in the decision to submit the article for publication.

\section{Conflict of interest}

The authors declare no conflict of interest.

\section{References}

1. Antony AC. In utero physiology: role of folic acid in nutrient delivery and fetal development. Am J Clin Nutr 2007; 85: 598S-603S.

2. Barua S, Kuizon S, Junaid MA. Folic acid supplementation in pregnancy and implications in health and disease. J Biomed Sci 2014; 21: 77.

3. Wen SW, Guo Y, Rodger M, et al. Folic acid supplementation in pregnancy and the risk of pre-eclampsia - a cohort study. PLoS One 2016; 11: e0149818.

4. Liu S, Joseph KS, Luo W, et al. Canadian Perinatal Surveillance System (Public Health Agency of Canada). Effect of folic acid food fortification in Canada on congenital heart disease subtypes. Circulation 2016; 134: 647-55.

5. Zheng JS, Guan Y, Zhao Y, et al. Pre-conceptional intake of folic acid supplements is inversely associated with risk of preterm birth and small-for-gestational-age birth: a prospective cohort study. Br J Nutr 2016; 115: 509-16.

6. McNulty B, McNulty H, Marshall B, et al. Impact of continuing folic acid after the first trimester of pregnancy: findings of a randomized trial of folic acid supplementation in the second and third trimesters. Am J Clin Nutr 2013; 98: 92-8.

7. Cheong M, Xiao HY, Tay V, et al. Folic acid fortified milk increases blood folate to concentrations associated with a very low risk of neural tube defects in Singaporean women of childbearing age. Asia Pac J Clin Nutr 2016; 25: 62-70.

8. Plumptre L, Masih SP, Ly A, et al. High concentrations of folate and unmetabolized folic acid in a cohort of pregnant Canadian women and umbilical cord blood. Am J Clin Nutr 2015; 102: 848-57.

9. Shen M, Chaudhry SH, MacFarlane AJ, et al. Serum and red-blood-cell folate demonstrate differential associations with $\mathrm{BMI}$ in pregnant women. Public Health Nutr 2016; 19: 2572-9.

10. Brouns R, Ursem N, Lindemans J, et al. Polymorphisms in genes related to folate and cobalamin metabolism and the associations with complex birth defects. Prenat Diagn 2008; 28: 485-93.

11. Monsen AL, Schneede J, Ueland PM. Mid-trimester amniotic fluid methionine concentrations: a predictor of birth weight and length. Metabolism 2006; 55: 1186-91.

12. Dawson EB, Evans DR, Harris WA, Van Hook JW. Amniotic fluid B12, calcium, and lead levels associated with neural tube defects. Am J Perinatol 1999; 16: 373-8.

13. Scheller K, Röckl T, Scheller C, Schubert J. Lower concentrations of B-vitamin subgroups in the serum and amniotic fluid correlate to cleft lip and palate appearance in the offspring of A/WySn mice. J Oral Maxillofac Surg 2013; 71: 1601.e1-7.

14. Washburn SE, Caudill MA, Malysheva O et al. Formate metabolism in fetal and neonatal sheep. Am J Physiol Endocrinol Metab 2015; 308: E921-7.
15. Underwood MA, Gilbert WM, Sherman MP. Amniotic fluid: not just fetal urine anymore. J Perinatology 2005; 25: 341-8.

16. Molloy AM, Scott JM. Microbiological assay for serum, plasma, and red cell folate using cryopreserved, microtiter plate method. Methods Enzymol 1997; 281: 43-53.

17. O'Broin S, Kelleher B. Microbiological assay on microtiter plates of folate in serum and red cells. J Clin Pathol 1992; 45: 344-7.

18. Adaikalakoteswari A, Vatish M, Lawson A, et al. Low maternal vitamin B12 status is associated with lower cord blood HDL cholesterol in white Caucasians living in the UK. Nutrients 2015; 7: 2401-14.

19. Ahn HS. Relation between folate levels of maternal-umbilical cord blood, placenta tissue and pregnancy outcomes. J Commun Nutrition 2004; 6: 91-6.

20. Caviedes L, Iñiguez G, Hidalgo P, et al. Relationship between folate transporters expression in human placentas at term and birth weights. Placenta 2016; 38: 24-28.

21. Fernàndez-Roig S, Cavallé-Busquets $P$, Fernandez-Ballart JD, et al. Low folate status enhances pregnancy changes in plasma betaine and dimethylglycine concentrations and the association between betaine and homocysteine. Am J Clin Nutr 2013; 97: 1252-9.

22. Yajnik CS, Deshpande SS, Jackson AA, et al. Vitamin B12 and folate concentrations during pregnancy and insulin resistance in the offspring: the Pune Maternal Nutrition Study. Diabetologia 2008; 51: 29-38.

23. Furness D, Fenech M, Dekker G, Khong TY, Roberts C, Hague W. Folate, vitamin B12, vitamin B6 and homocysteine: impact on pregnancy outcome. Matern Child Nutr 2013; 9: 155-66.

24. Kocyłowski R, Lewicka I, Grzesiak M, et al. Assessment of dietary intake and mineral status in pregnant women. Arch Gynecol Obstet 2018; 297: 1433-40.

25. Bomba-Opoń D, Hirnle L, Kalinka J, Seremak-Mrozikiewicz A. Folate supplementation during the preconception period, pregnancy and puerperium. Polish Society of Gynecologists and Obstetricians Guidelines. Ginekol Perinatol Prakt 2017; 2: 210-4.

26. Chen LW, Lim AL, Colega M, et al. Maternal folate status, but not that of vitamins B12 or B6, is associated with gestational age and preterm birth risk in a multiethnic Asian population. J Nutr 2015; 145: 113-20.

27. Nilsen RM, Vollset SE, Monsen ALB, et al. Infant birth size is not associated with maternal intake and status of folate during the second trimester in Norwegian pregnant women. J Nutr 2010; 140: 572-9.

28. Saccone G, Berghella V. Folic acid supplementation in pregnancy to prevent preterm birth: a systematic review and meta-analysis of randomized controlled trials. Eur J Obstet Gynecol Reprod Biol 2016; 199: 76-81.

29. Tinker SC1, Hamner HC, Berry RJ, Bailey LB, Pfeiffer CM. Does obesity modify the association of supplemental folic acid with folate status among nonpregnant women of childbearing age in the United States? Birth Defects Res A Clin Mol Teratol 2012; 94: 749-55.

30. Stern SJ, Matok I, Kapur B, Koren G. A comparison of folic acid pharmacokinetics in obese and nonobese women of childbearing age. Ther Drug Monit 2011; 33: 336-40.

31. Maffoni S, De Giuseppe R, Stanford FC, Cena H. Folate status in women of childbearing age with obesity: a review. Nutr Res Rev 2017; 7 : 1-7.

32. Biesiada LA, Głowacka E, Krekora M, Sobantka S, Krokocka A, Krasomski G. The impact of excessive maternal weight on the nutritional status of the fetus - the role of leptin. Arch Med Sci 2016; 12: 394-401. 
33. Gutaj P, Wender-Ożegowska E, Brązert J. Maternal lipids associated with large-for-gestational-age birth weight in women with type 1 diabetes: results from a prospective single-center study. Arch Med Sci 2017; 13: 753-9.

34. Chitayat D, Matsui D, Amitai Y, et al. Folic acid supplementation for pregnant women and those planning pregnancy: 2015 update. J Clin Pharmacol 2016; 56: 170-5.

35. Shi Y, De Groh M, MacFarlane AJ. Socio-demographic and lifestyle factors associated with folate status among non-supplement-consuming Canadian women of childbearing age. Can J Public Health 2014; 105: e166-171.

36. Marchetta CM, Devine OJ, Crider KS, et al. Assessing the association between natural food folate intake and blood folate concentrations: a systematic review and Bayesian meta-analysis of trials and observational studies. Nutrients 2015; 7: 2663-86

37. Kulhan M, Kulhan NG, Nayki UA, et al. Assessment of the relationship between serum vitamin (A, B12, C, D, folate) and zinc levels and polycystic ovary syndrome. Arch Med Sci Civil Dis 2017; 2: e62-9.

38. Yila TA, Araki A, Sasaki S, et al. Predictors of folate status among pregnant Japanese women: the Hokkaido Study on Environment and Children's Health, 2002-2012. Br Nutr 2016; 115: 2227-35.

39. Branum AM, Bailey R, Singer BJ. Dietary supplement use and folate status during pregnancy in the United States. J Nutr 2013; 143: 486-92. 